\title{
Association of firearm exposure during youth with lifetime incidence of suicide ideation and suicide attempts
}

\section{Craig J. Bryan ( $\nabla$ craig.bryan@osumc.edu )}

The Ohio State University Wexner Medical Center

AnnaBelle 0. Bryan

The Ohio State University Wexner Medical Center

Michael D. Anestis

Rutgers, The State University of New Jersey

\section{Research Article}

Keywords: firearms, suicide ideation, suicide attempt

Posted Date: February 16th, 2021

DOI: https://doi.org/10.21203/rs.3.rs-199622/v1

License: (c) (i) This work is licensed under a Creative Commons Attribution 4.0 International License.

Read Full License 


\section{Abstract}

Background: Preliminary evidence suggests firearm availability may increase the risk for suicide ideation and attempts, two common precursors to suicide death. Little is known about which aspects of firearm availability may account for this association. The primary purpose of this study was to examine associations among multiple dimensions of firearm availability with lifetime history of suicide ideation and attempts.

Methods: A cross-sectional, anonymous survey was administered to 6200 U.S. adults from March 5, 2020, to March 17, 2020. Participants were asked to report firearm availability, firearm use, and suicidal thoughts and behaviors over the lifespan.

Results: Rates of lifetime suicide ideation were significantly elevated among participants reporting a firearm in their childhood home (odds ratio $[\mathrm{OR}]=1.3,95 \%$ confidence interval $[\mathrm{Cl}]=1.1-1.5$ ). Rates of lifetime suicide attempt were significantly elevated among participants reporting a firearm in their childhood home (OR=1.8, 95\% $\mathrm{Cl}=1.5-2.2)$ and participants who first acquired a firearm before the age of $11(\mathrm{OR}=3.8,95 \% \mathrm{Cl}=2.6-5.8)$. Among participant with a lifetime history of suicide ideation, rates of lifetime suicide attempt were significantly elevated among participants who first acquired a firearm before the age of $11(\mathrm{OR}=3.0,95 \% \mathrm{Cl}=1.4-6.4)$, but this relationship was no longer significant when adjusting for demographics and negative affectivity $(\mathrm{OR}=2.4,95 \% \mathrm{Cl}=0.96-6.0)$.

Conclusions: Adults who were raised in a home with a firearm and/or first acquired a firearm were significantly more likely to have attempted suicide during their lives. Additional research examining the mechanisms by which early life firearm exposure might increase suicide risk across the lifespan is warranted.

\section{Introduction}

Firearms account for more than half of U.S. suicides. ${ }^{1}$ Multiple lines of evidence utilizing a range of research methods including cross-sectional and longitudinal designs, as well as state-level and individual-level data, support a positive correlation between firearm availability and suicide. Households with firearms, for instance, have significantly higher rates of suicide than households with no firearms. ${ }^{2,3}$ When firearms availability is reduced via safe storage methods (e.g., use of locking devices), however, suicide risk is reduced. ${ }^{4}$ Research also shows that states with firearm laws that regulate access to firearms have lower suicide rates than states with less restrictive laws. ${ }^{5,6}$ Policy and legislative changes that restrict or reduce firearm availability have also led to declines in suicide rates. ${ }^{7-10}$

Although firearm availability increases the risk of suicide mortality across all age groups, evidence suggests that younger age groups (i.e., children and young adults) may be disproportionately impacted. $3,11,12$ In the U.S., an estimated $18-24 \%$ of adolescents report having access to firearms in their homes $^{13}$ and $10-24 \%$ report owning their own firearm. ${ }^{14,15}$ Firearm ownership is more common among 
male and white adolescents, and increases with age among boys, ${ }^{14}$ mirroring trends in suicide mortality among children, adolescents, and young adults. ${ }^{1}$ The correlation of firearm availability with suicide among children, adolescents, and young adults may be due to higher levels of impulsivity during these developmental stages. ${ }^{11}$ From this perspective, firearm availability contributes to suicide mortality by increasing the probability that a suicide attempt will be fatal.

An alternative possibility is that firearm availability contributes to suicide mortality by increasing an individual's propensity to engage in suicidal behaviors, often referred to as suicidal capability in contemporary theories of suicide like the interpersonal psychological theory, the three-step theory, and the integrated motivational volitional theory. ${ }^{16-18}$ According to these theories, suicidal capability can be acquired through habituation to painful and provocative experiences that are associated with pain, injury, fear, and death. From this biobehavioral perspective, firearm availability-notably firearm access and firearm use-increases the risk of suicide mortality in part through its influence on suicidal capability. ${ }^{19}$ Supporting this perspective is research finding a positive association between firearm availability and nonfatal suicidal behaviors. Adolescents who report carrying a weapon while on school property, for instance, are significantly more likely to have made a nonfatal suicide attempt. ${ }^{20}$ Evidence also suggests that although adults who have previously attempted suicide are less likely to live in a household with a firearm, ${ }^{21}$ adults who live a household with a firearm are more likely to have made a suicide attempt within the preceding year. ${ }^{22}$ Importantly, these studies have not found a correlation of firearm availability with suicide ideation, however, a pattern that aligns with the conceptualization of suicidal capability as a volitional factor that primarily influences decision-making processes (e.g., to act or not to act). ${ }^{16-18}$ Consistent with this distinction, research with suicidal military personnel suggests that increased firearm availability (i.e., having access to loaded and unsecured firearms in one's household) is not associated with severity of suicide ideation but is associated with a stronger expectation of acting upon suicidal thoughts. $^{23}$

Central to the acquired suicidal capability hypothesis is that vulnerability to engaging in suicidal behaviors accumulates as a result of repeated or prolonged exposure to painful and provocative experiences. Accordingly, firearm acquisition and use earlier in the lifespan should be associated with increased risk for suicidal behaviors, whether fatal or nonfatal, owing to the accumulation of capability over time. The relationship of prolonged or extended periods of firearm availability with nonfatal suicidal behaviors is therefore especially relevant to the acquired capability hypothesis because the highly lethal nature of firearms would reasonably be expected to reduce the probability of surviving a suicide attempt. Specifically, if longer periods of firearm availability are positively correlated with risk of nonfatal suicide attempts, that would support the hypothesis of acquired suicidal capability.

Unfortunately, studies investigating the association of firearm availability with suicidal thoughts and behaviors have predominantly focused on testing their associations with current firearm availability (e.g., currently living in a household with a firearm, current firearm ownership). Further research examining the associations among suicidal thoughts and behaviors with multiple aspects of firearm availability over 
different timeframes could reveal new perspectives for understanding the correlation of firearms and suicide mortality, and may implicate new intervention targets for suicide prevention. In the present study, we pursued this objective by examining associations among multiple dimensions of firearm availabilitypresence of a firearm in a childhood home, age when someone first acquired a firearm, age when someone first shot a firearm, and current firearm ownership-with lifetime history of suicide ideation and suicide attempts in a large sample of U.S. adults.

\section{Methods}

\section{Participants and Procedures}

Participants were recruited by Qualtrics Panels, a market research company that maintains a list of several million U.S. adults who have agreed to complete research surveys. Potential participants were invited to participate using quota sampling methods via email invitation with an embedded hyperlink to an online survey. Quota sampling was selected for because our primary aim was to examine relationships among variables of interest that were expected to vary across demographic subgroups. In contrast to convenience or snowball sampling, quota sampling can ensure sufficient demographic representation. We did not have sufficient resources to use probabilistic sampling methods, however. Subgroup quotes were selected to match the 2010 U.S. Census data as closely as possible based on the following variables: biological sex, age, race and ethnicity, annual household income, and geographic region. Email invitations did not include any information about the purpose or content of the survey, but only included information about the survey's estimated duration (i.e., 15 minutes) and incentive value (e.g., 145 points). Panel members were required to review an informed consent form that described the purpose of the study prior to completing the survey, which took a median of 11.3 minutes to complete. The stated purpose of the survey in the informed consent form was "to understand how perceptions of safety, perceptions about oneself, and life experiences are associated with the use of various methods for self-protection." Participants who completed the survey were compensated in the amount agreed upon when they signed up for the panel. This study's procedures were reviewed and approved by the Institutional Review Board at the University of Utah.

\section{Measures}

Suicidal Thoughts and Behaviors. The Self-Injurious Thoughts and Behaviors Interview-Revised ${ }^{24}$ was used to assess lifetime history of suicide ideation and attempts. Items used to assess lifetime history of suicide ideation and suicide attempts are listed in Table 1. A positive history of each was indicated by a participant endorsing any of the items within each category.

Firearm Exposure. Four aspects of firearm exposure were measured (see Table 1). The first item assessing current firearm availability was developed by the Centers for Disease Control and Prevention for the Behavioral Risk Factor Surveillance System. ${ }^{25}$ The second item assessing firearm availability during childhood was developed for this survey by the researchers to mirror the language and structure of 
the CDC item. Finally, the third and fourth items assessing the age when participants first shot a firearm and first acquired a firearm were developed for this survey by the researchers with input from firearm owners serving in an advisory capacity. The age groupings used in the third and fourth items were selected to correspond with the following developmental stages: preadolescence (10 years and younger), early adolescence (11-15 years), middle adolescence to young adulthood (16-25 years), and adulthood (26 years and older).

Negative and Positive Affect. The International Positive and Negative Affect Schedule Short Form (IPANAS-SF) ${ }^{26}$ was used to assess negative affectivity during the past week. The I-PANAS-SF measures each mood state with items that are rated on a 5-point scale ranging from "very slight or not at all" to "extremely." Items are summed to obtain a total score, with high scores indicating more intense affect. Because negative affectivity has been shown to influence our firearm acquisition ${ }^{27-29}$ and suicidal thoughts and behaviors, ${ }^{30}$ we included this variable as a covariate.

\section{Data Analytic Approach}

A series of univariate and multivariate logistic regression models were constructed with lifetime history of suicide ideation and lifetime history of suicide attempt entered as separate outcomes. We first entered each of the four firearm exposure variables as independent predictor variables in separate models, then tested multivariate models with all four firearm exposure variables entered simultaneously, thereby enabling us to examine relationships while accounting for all other aspects of firearm exposure. Finally, negative affectivity and sociodemographic variables (i.e., sex, age, White versus non-White race) were added as covariates to further test the robustness of observed findings. A total of 82,647 panel members received an email invitation, of which 10,368 opened the survey and 6200 completed the survey. Survey open rates and completion rates were higher than recent reports using similar recruitment and sampling methods. ${ }^{29}$ Data were missing from fewer than $0.5 \%$ of participants who completed the survey. We used a combination of p-values, effect size magnitude (i.e., odds ratios), and confidence intervals to assess the significance of findings. Specifically, we considered findings with $\mathrm{p}<.01, \mathrm{OR}>1.5$ (or the inverse, $\mathrm{OR}<0.67$ ), and a $95 \%$ confidence interval that did not include the value 1 to be significant. All analyses were conducted using SPSS version 25 software with two-tailed tests. Our sample size $(\mathrm{N}=6200)$ was established based on the results of a priori power analyses with the following assumptions: a minimum effect size threshold of $O R=1.5$, a binary outcome (i.e., lifetime history of suicide attempt) that we estimated would be reported by $5 \%$ of the sample, a binary independent variable with a minimum incidence rate of $25 \%$, a minimum of $90 \%$ power, and a two-tailed $a=.05$.

\section{Results}

The demographic profile of the sample is summarized in Table 2. The lifetime prevalence of suicide ideation and suicide attempts were $14.1 \%$ and $7.2 \%$, respectively. Rates of lifetime suicide ideation and suicide attempt by demographic category are also summarized in Table 2. The mean negative affect score was $10.1(\mathrm{SD}=4.7)$ and was comparable to previously published scores among U.S. adults. ${ }^{26} 2311$ 
(37.3\%) participants reported currently having a firearm in or around their home, and 2372 (38.3\%) reported there being a firearm in their childhood home.

\section{Intercorrelations of firearm exposure variables}

To assess the extent to which our four firearm exposure variables were interrelated, all of which were categorical in nature, we used chi-square analyses and calculated Cramer's V statistics. Results are summarized in Table 3. Overall, $\mathrm{V}$ statistics indicated firearm exposure variables were moderately and significantly intercorrelated, suggesting they were related but distinct aspects of firearm exposure.

\section{Association of childhood firearm exposure with lifetime suicidal thoughts and behaviors}

Results of univariate and multivariate logistic regression models are reported in Table 4. Rates of lifetime suicide ideation were significantly higher among participants who grew up with a firearm in their childhood home. Rates of lifetime suicide attempts were significantly higher among participants who grew up with a firearm in their childhood home, first shot a firearm during adulthood, and first acquired a firearm before the age of 11 .

Among participants with a lifetime history of suicide ideation, rates of lifetime suicide attempts were also higher among participants reporting a firearm in their childhood home and participants who first shot a firearm before the age of 11 , but this relationship only trended towards statistical significance in our second multivariate model that adjusted for sociodemographics and negative affectivity. We alternately removed negative affectivity and the sociodemographic variables from the model, and found that acquiring a firearm before the age of 11 remained a statistically significant correlate of lifetime suicide attempts when negative affectivity was removed from the model (adjusted odds ratio [aOR] $=2.72,95 \%$ confidence interval $[\mathrm{Cl}]=1.10-6.74])$ but not when sociodemographic variables were removed $(\mathrm{aOR}=2.23$, $95 \% \mathrm{Cl}=0.91-5.44)$, suggesting the association of early childhood firearm exposure with suicide attempts among those who have thought about suicide may have been explained by heightened negative affectivity.

\section{Discussion}

Firearm availability is positively correlated with suicide mortality due in part to its highly profile, which increases the probability that suicide attempts will be fatal. The present findings suggest that firearm availability may also contribute to suicide mortality by increasing the probability of acting upon suicidal urges, an effect that has been hypothesized by contemporary theories of suicide. ${ }^{16-18}$ According to these theories, repeated and prolonged exposure to stimuli that are associated with pain, injury, and death can increase an individual's capacity for engaging in suicidal behaviors. Previous research has reported positive correlations between current firearm availability and various aspects of suicidal capabilitynamely suicide attempts ${ }^{20,21}$ and suicidal intent ${ }^{23}$-but to our knowledge, this is the first study to examine associations among extended or prolonged firearm exposure and availability across the lifespan with these outcomes. 
Consistent with the notion of acquired capability for suicide, participants were significantly more likely to have made a suicide attempt during their lives if they first acquired a firearm during preadolescence (i.e., prior to 11 years of age). Over three-quarters of this subgroup reported growing up with a firearm in the home and first shot a firearm prior to 11 years of age, indicating that early firearm acquisition is strongly correlated with multiple dimensions of firearm availability and exposure. Of note, participants who first acquired a firearm during preadolescence were over three times more likely to have attempted suicide than participants who never acquired a firearm (19.2\% vs. $5.8 \%)$. When constraining our analyses to those participants with a lifetime history of suicide ideation, acquiring a firearm during preadolescence was a significant correlate of suicide attempts, although this difference was no longer statistically significant when adjusting for current negative affectivity. Owing to our cross-sectional design, we are unable to determine if this represents mediation, confounding, or suppression, although some research with adults suggests that firearm acquisition and negative affectivity have a bidirectional relationship, akin to a positive feedback loop. ${ }^{29}$ Those findings may not generalize to firearm acquisition during early childhood, however, because the methods use for firearm acquisition during childhood and adulthood likely differ. State and federal law, for instance, have established minimum firearm purchase and possession ages (typically 18-21 years, although some states have minimum ages of 16 ) 8,31 that restricts opportunities for children to legally acquire firearms on their own.

Participants who reported growing up in a home with a firearm also reported significantly increased rates of suicide attempts. In contrast to our findings specific to preadolescent firearm acquisition, however, having a firearm in one's childhood home were also associated with higher rates of suicide ideation ( $15.6 \%$ for those reporting a firearm in their childhood home versus $12.6 \%$ for those reporting no firearms in their childhood home). Although firearm availability during childhood was associated with suicide ideation and attempts, current firearm ownership was not, consistent with previous studies using nationally representative samples. ${ }^{21,22}$ Longitudinal research beginning in preadolescence is needed to better understand how the timing of firearm acquisition, negative affectivity, suicide ideation, and suicide attempts are temporally related. Overall, however, these findings suggest that even relatively milder forms of firearm exposure during childhood were associated with increased risk for suicidal thoughts and behaviors in our sample. Presumably the excess suicide attempts reported by participants reporting childhood firearm availability rarely, if ever, involved a firearm, thereby increasing the plausibility of survival.

In general, participants who had ever shot a firearm were more likely than those who had never shot a firearm to report a suicide attempt, consistent with the notion of acquired capability for suicide. In our adjusted models, only those participants who had first shot a firearm during adulthood had significantly elevated suicide attempts rates; those who had first shot firearms earlier in life did not have elevated suicide attempt rates, however, as would be hypothesized by contemporary theories based on the assumption that firearm use earlier in life would reflect higher levels of familiarity and exposure. This pattern may implicate different mechanisms underlying the relationships among firearm acquisition, firearm use, and suicidal thoughts and behaviors, and warrants further investigation. 
Previous research has focused primarily on the correlation of firearm availability with suicide mortality. Although this research has provided important information about mortality risks associated with firearms, our understanding of how firearm exposure might be related to a broader range of adverse outcomes remains limited. The present study therefore expands our knowledge about different aspects of firearm exposure are correlated with other manifestations of suicide risk, notably suicide ideation and nonfatal suicide attempts, two common precursors to suicide death. ${ }^{29}$ One possible implication of these results is that national suicide rates could be positively impacted via efforts aimed at limiting or restricting firearm availability during early childhood. As noted before, state and federal laws currently restrict firearm purchase by most children and adolescents. ${ }^{8,31}$ Overall, the effects of these laws on suicide rates are inconclusive. ${ }^{8-10,31-33}$ The majority of these studies focused on suicide mortality in the youngest age groups (<21 years of age) and did not investigate effects at the individual level, however, thereby precluding the ability to account for actual access and use of firearms during childhood at the person level and the possibility for delayed effects across the lifespan. Person-level analyses may therefore provide novel information about how firearm availability and suicide risk are related, thereby complementing previous research, the majority of which has examined aggregate correlations.

Unfortunately, the present study is unable to elucidate the mechanisms underlying the observed associations. One possibility is that early firearm exposure adversely effects cognitive control processes, a possibility implicated by laboratory-based studies showing increased reactivity and behavioral impulsivity among young adults while they are in physical possession of a firearm. ${ }^{34,35}$ Another possibility is that firearm exposure during early childhood serves as a proxy for other risk factors for suicide. Firearm acquisition and ownership, for example, are associated with higher rates of interpersonal trauma and victimization, ${ }^{36-38}$ each of which can lead to increased negative affectivity. Firearm availability during early childhood may therefore reflect exposure to other environmental, interpersonal, and/or psychological risk factors for suicide. Longitudinal studies are needed to test these possibilities.

Conclusions based on the present study are also limited by our self-report methodology, which could be vulnerable to response bias, although the anonymous response format of our survey likely improved selfdisclosure of sensitive items. ${ }^{39,40}$ Our study is also limited by the use of quota sampling, which precludes our ability to know how representative our sample was of all U.S. adults. Because we did not use probabilistic sampling methods, our results could be biased to an unknown degree. Another related limitation is our inability to determine how similar (or not) survey completers were relative to all of the panel members who received an invitation to participate. Despite these limitations, quota sampling provides some advantages over convenience sampling and snowball sampling, namely ensuring sufficient participation of individuals from subgroups of interest. Although our sampling approach restricts the types of inferences that can be made, we were nonetheless able to examine relationships among variables and characteristics of interest across multiple subgroups-a primary reason for using quota sampling. Conclusions based on the present results should therefore be made cautiously and be considered preliminary until further research using probabilistic sampling methods can be accomplished. 
Another limitation is the omission of any survey items that assess the extent to which participants identified as firearm owners, another related facet of firearm availability that could be relevant to suicide risk. A final limitation involves the timing of our data collection, which occurred during the first month of the novel coronavirus (COVID-19) outbreak in the U.S. Firearm purchases have increased sharply during the COVID-19 pandemic ${ }^{41}$ suggesting secular effects that may have influenced participant response patterns. Despite these limitations, our results suggest that certain aspects of firearm availability, especially firearm exposure during early childhood, was associated with increased risk for suicide ideation and suicide attempts, and warrant further empirical investigation aimed at reducing suicide.

\section{Declarations}

\section{Ethics approval and consent to participate}

This study was reviewed and approved by The University of Utah Institutional Review Board (IRB_00130434). This study presented no more than minimal risk of harm to subjects and involved no procedures for which written consent is normally required outside of the research context. We were therefore granted a waiver of documentation of consent. An information sheet outlining the study's purposes, procedures, and potential risks were described on the first page of the electronic survey along with the principal investigator's name and contact information. All participants consented by proceeding to the second page of the survey. All methods were performed in accordance with the Declaration of Helsinki and all other relevant guidelines and regulations.

\section{Consent for publication}

Not applicable

\section{Availability of data and materials}

The datasets used and/or analyzed during the current study are available from the corresponding author on reasonable request.

\section{Competing interests}

The authors declare that they have no competing interests.

\section{Funding}

Not applicable

\section{Authors' contributions}

$\mathrm{CJB}$ and $\mathrm{AOB}$ generated the research idea, obtained regulatory approval, and collected data. CJB analyzed the data. CJB, AOB, and MDA interpreted the results and wrote the manuscript. 
Acknowledgements

None

References 
1. Centers for Disease Control and Prevention, National Center for Injury Prevention and Control. Web-based Injury Statistics Query and Reporting System (WISQARS) [online].

http://www.cdc.gov/injury/wisqars. Published 2005. Accessed September 2, 2020.

2. Anglemyer A, Horvath T, Rutherford G. The accessibility of firearms and risk for suicide and homicide victimization among household members: a systematic review and meta-analysis. Ann Int Med. 2014;160:101-10.

3. Miller M, Lippmann SJ, Azrael D, Hemenway D. Household firearm ownership and rates of suicide across the 50 United States. J Trauma Acute Care Surg. 2007;62:1029-35.

4. Shenassa ED, Rogers ML, Spalding KL, Roberts MB. Safer firearm storage of firearms at home and risk of suicide: a study of protective factors in a nationally representative sample. J Epi Commun Health. 2004;58:841-8.

5. Anestis MD, Anestis JC. Suicide rates and state laws regulating access and exposure to handguns. Am J Public Health. 2015;105:2049-58.

6. Anestis MD, Anestis JC, Butterworth SE. Handgun legislation and changes in statewide overall suicide rates. Am J Public Health. 2017;107:579-81.

7. Lubin $G$, Werbeloff $N$, Halperin $D$ et al. Decrease in suicide rates after a change of policy reducing access to firearms in adolescents: a naturalistic epidemiological study. Suicide Life-Threat Beh. 2010;40:421-4.

8. Webster DW, Vernick JS, Zeoli AM, Manganello JA. Association between youth-focused firearm laws and youth suicides. JAMA. 2004; 292:594-601.

9. Gius M. The impact of minimum age and child access prevention laws on firearm-related youth suicides and unintentional deaths. Soc Sci J. 2015;52:168-75.

10. Andrés AR, Hempstead K. Gun control and suicide: The impact of state firearm regulations in the United States, 1995-2004. Health Policy. 2011;101:95-103.

11. Miller M, Azrael D, Hemenway D. Household firearm ownership and suicide rates in the United States. Epidemiology. 2002;13:517-24.

12. Kellermann AL, Rivara FP, Somes G, Reay DT, Francisco J, Banton JG, Prodzinski J, Fligner C, Hackman BB. Suicide in the home in relation to gun ownership. New Eng J Med. 1992;327:467-72.

13. Cretacci MA, Hendrix N. Close range: Adolescent predictors of adult firearm ownership in the United States. Int J Crim Justice Sci. 2017;12:285-301.

14. Sadowski LS, Cairns RB, Earp JA. Firearm ownership among nonurban adolescents. Am J Dis Child. 1989; 143:1410-3.

15. Lizotte AJ, Tesoriero JM, Thornberry TP, Krohn MD. Patterns of adolescent firearms ownership and use. Justice Quart. 1994;11:51-74.

16. Van Orden KA, Witte TK, Cukrowicz KC, Braithwaite SR, Selby EA, Joiner Jr TE. The interpersonal theory of suicide. Psychological review. 2010;117:575-600.

17. O'Connor RC, Kirtley OJ. The integrated motivational-volitional model of suicidal behaviour. Phil Trans Royal Soc B: Biol Sci. 2018;373:20170268.

18. Klonsky ED, May AM. The three-step theory (3ST): A new theory of suicide rooted in the "ideationto-action" framework. Int J Cog Ther. 2015;8:114-29.

19. Klonsky ED, Qiu T, Saffer BY. Recent advances in differentiating suicide attempters from suicide 
ideators. Cürr Opinion Psychiatry. 2017;30:15-20.

20. Baiden P., Tadeo SK, Graaf G, Respress BN. Examining the association between weapon carrying on school property and suicide attempt among adolescents in the United States. Soc Work Public Health. 2019;34:570-82.

21. Ilgen MA, Zivin K, McCammon RJ, Valenstein M. Mental illness, previous suicidality, and access to guns in the United States. Psychiatric Services. 2008;59:198-200.

22. Miller M, Barber C, Azrael D, Hemenway D, Molnar BE. Recent psychopathology, suicidal thoughts and suicide attempts in households with and without firearms: findings from the National Comorbidity Study Replication. Inj Prev. 2009;15:183-7.

23. Khazem LR, Houtsma C, Gratz KL et al. Firearms matter: the moderating role of firearm storage in the association between current suicidal ideation and likelihood of future suicide attempts among United States military personnel. Mil Psychol. 2015;28:25-33.

24. Fox, KR, Harris JA, Wang SB et al. Self-Injurious Thoughts and Behaviors Interview-Revised: development, reliability, and validity. Psychol Assess. 2020;32:677-89.

25. Centers for Disease Control and Prevention (CDC). Behavioral Risk Factor Surveillance System Survey Questionnaire. Atlanta, Georgia: U.S. Department of Health and Human Services, Centers for Disease Control and Prevention, 2017.

26. Karim J, Weisz R, Rehman SU. International positive and negative affect schedule short-form (IPANAS-SF): testing for factorial invariance across cultures. Pocedia Soc Behav Sci. 2011;15:20162022.

27. Bryan CJ, Bryan AO, Anestis MD. Associations among exaggerated threat perceptions, suicidal thoughts, and suicidal behaviors in US firearm owners. J Psychiatric Res. 2020;131:94-101.

28. Anestis MD, Bryan CJ. Threat perceptions and the intention to acquire firearms. J Psychiatric Res. 2020;133:113-118.

29. Bryan CJ, Anestis MD, Bryan AO. Positive and negative affective processes associated with firearm acquisition and ownership. J Soc Clin Psychol. In press.

30. Franklin JC, Ribeiro JD, Fox KR, Bentley KH, Kleiman EM, Huang X, Musacchio KM, Jaroszewski AC, Chang BP, Nock MK. Risk factors for suicidal thoughts and behaviors: a meta-analysis of 50 years of research. Psych Bull. 2017;143:187-232.

31. Smart R, Morral AR, Smucker S et al. The science of gun policy: a critical synthesis of research evidence on the effects of gun policies in the United States. $2^{\text {nd }}$ Ed. RAND Corporation; 2020.

32. Marvell TB. The impact of banning juvenile gun possession. J Law Econ. 2001;44:691-713.

33. Rosengart $M$, Cummings $P$, Nathens $A$, et al. An evaluation of state firearm regulations and homicide and suicide death rates. Injury Prevention. 2005;11:77-83.

34. Taylor JET, Witt JK, Pratt J. A different kind of weapon focus: simulated training with ballistic weapons reduces change blindness. Cog Res: Princ Implications. 2017;2:3.

35. Witt JK, Brockmole JR. Action alters object identification: wielding a gun increases the bias to see guns. J Exp Psychol: Hum Percept Perform. 2012;38:1159-1167.

36. Vaughn MG, Howard MO, Harper-Chang L. Do prior trauma and victimization predict weapon carrying among delinquent youth? Youth Violence and Juvenile Justice. 2006;4:314-27.

37. Beardslee J, Mulvey E, Schubert C et al. Gun and non-gun related violence exposure and risk for 
subsequent gun carrying among male juvenile offenders. J Am Acad Child Adolesc Pscyhiatry. 2018; 57:274-79.

38. Spano R, Pridemore WA, Bolland J. Specifying the role of exposure to violence and violent behavior on initiation of gun carrying: a longitudinal test of three models of youth gun carrying. $J$ Interpers Violence. 2012;27:158-76.

39. McLay RN, Deal WE, Murphy JA et al. On-the-record screenings versus anonymous surveys in reporting PTSD. Am J Psychiatry. 2008;165:775-6.

40. Anestis MD, Green BA. The impact of varying levels of confidentiality on disclosure of suicidal thoughts in a sample of United States National Guard personnel. J Clin Psycho. 2015;71:1023-30.

41. Levine PB, McKnight R. Three million more guns: the spring 2020 spike in firearm sales. https://www.brookings.edu/blog/up-front/2020/07/13/three-million-more-guns-the-spring-2020-spikein-firearm-sales/. Published 2020. Accessed September 2, 2020.

\section{Tables}

Table 1.

Item content and response options used to assess lifetime history of suicidal thoughts and behaviors and firearm exposure 


\section{Suicide ideation items}

Have you ever had any of the following thoughts for more than a few minutes?

"I should kill myself"

"I am going to kill myself"
No

Yes

No

Yes

\section{Suicide attempt items}

Have you ever done any of the following?

Started to kill yourself and then you stopped after you had already taken No some action.

Yes

Started to kill yourself and then you decided to reach out for help after you

No

already taken some action.

Yes

Tried to kill yourself and someone found you afterwards.

No

Yes

Tried to kill yourself and no one found you afterwards.

No

Yes

\section{Firearm exposure items}

Do you currently have a firearm in or around your home?

No

Yes

Don't know

Prefer not to answer

Were there any firearms in your childhood home?

No

Yes

Don't know

Prefer not to answer

How old were you when you first shot a firearm?

I have never shot a firearm

Under 11 years old

11-15 years old

$16-25$ years old

26-30 years old

Over 30 years old

How old were you when you acquired your first firearm?

I have never acquired a firearm

Under 11 years old

11-15 years old

16-25 years old

26-30 years old

Over 30 years old

Table 2 . 
Demographic characteristics of the full sample and rates of lifetime suicide ideation and suicide attempt within each demographic category

\begin{tabular}{|c|c|c|c|}
\hline & Full Sample & Lifetime SI & Lifetime SA \\
\hline Variable & $\mathrm{n}(\%)$ & $\mathrm{n}(\%)$ & $\mathrm{n}(\%)$ \\
\hline \multicolumn{4}{|l|}{ Sex } \\
\hline Male & 3038 (49.0\%) & 366 (12.0\%) & 202 (6.6\%) \\
\hline Female & 3162 (51.0\%) & 508 (16.1\%) & $242(7.7 \%)$ \\
\hline \multicolumn{4}{|l|}{ Gender } \\
\hline Male & 3019 (48.7\%) & 362 (12.0\%) & $201(6.7 \%)$ \\
\hline Female & 3150 (50.8\%) & $497(15.8 \%)$ & $237(7.5 \%)$ \\
\hline Transgender & $16(0.3 \%)$ & $6(37.5 \%)$ & $2(12.5 \%)$ \\
\hline Other & $15(0.2 \%)$ & $9(60.0 \%)$ & $4(26.7 \%)$ \\
\hline \multicolumn{4}{|l|}{ Age } \\
\hline $18-24 \mathrm{y}$ & 643 (10.4\%) & 201 (31.3\%) & 67 (10.4\%) \\
\hline $25-34 \mathrm{y}$ & $1217(19.6 \%)$ & 249 (20.5\%) & 125 (10.3\%) \\
\hline $35-44 y$ & $1313(21.2 \%)$ & 204 (15.5\%) & $146(11.1 \%)$ \\
\hline $45-54 y$ & 857 (13.8\%) & $99(11.6 \%)$ & $60(7.0 \%)$ \\
\hline $55-64 y$ & 1136 (18.3\%) & $80(7.0 \%)$ & $30(2.6 \%)$ \\
\hline $65-74 y$ & 845 (13.6\%) & $35(4.1 \%)$ & $13(1.5 \%)$ \\
\hline $75-84 y$ & $181(2.9 \%)$ & $6(3.3 \%)$ & $3(1.7 \%)$ \\
\hline $85+\mathrm{y}$ & $8(0.1 \%)$ & $0(0.0 \%)$ & $0(0.0 \%)$ \\
\hline \multicolumn{4}{|l|}{ Race } \\
\hline White & $4041(65.2 \%)$ & $548(13.6 \%)$ & $281(7.0 \%)$ \\
\hline Hispanic, Latino, Spanish origin & $919(14.8 \%)$ & $190(20.7 \%)$ & $96(10.4 \%)$ \\
\hline Asian & $861(13.9 \%)$ & $113(13.1 \%)$ & $44(5.1 \%)$ \\
\hline Black & $770(12.4 \%)$ & $135(15.4 \%)$ & $73(9.5 \%)$ \\
\hline Native American & $288(4.6 \%)$ & $75(26.0 \%)$ & $42(9.5 \%)$ \\
\hline Pacific Islander & $62(1.0 \%)$ & $17(27.4 \%)$ & $9(14.5 \%)$ \\
\hline Other & $448(7.2 \%)$ & $78(17.4 \%)$ & $44(9.9 \%)$ \\
\hline \multicolumn{4}{|l|}{ Gun in home currently } \\
\hline No & $3729(60.1 \%)$ & $522(14.0 \%)$ & $229(6.1 \%)$ \\
\hline Yes & $2311(37.3 \%)$ & $331(14.3 \%)$ & $206(8.9 \%)$ \\
\hline I don't know ${ }^{\mathrm{a}}$ & -- & -- & -- \\
\hline Prefer not to answer & $160(2.6 \%)$ & $21(13.1 \%)$ & $9(5.6 \%)$ \\
\hline \multicolumn{4}{|l|}{ Gun in home as child } \\
\hline No & $3318(53.5 \%)$ & $419(12.6 \%)$ & $185(5.6 \%)$ \\
\hline Yes & $2372(38.3 \%)$ & $369(15.6 \%)$ & $230(9.7 \%)$ \\
\hline I don't know & $436(7.0 \%)$ & $76(17.4 \%)$ & $28(6.4 \%)$ \\
\hline Prefer not to answer & $74(1.2 \%)$ & $10(13.5 \%)$ & $1(1.4 \%)$ \\
\hline \multicolumn{4}{|l|}{ Age when first shot firearm } \\
\hline Never shot firearm & $2273(36.7 \%)$ & $345(15.2 \%)$ & $128(5.6 \%)$ \\
\hline$\leq 11 \mathrm{y}$ & $742(12.0 \%)$ & $109(14.7 \%)$ & $72(9.7 \%)$ \\
\hline $11-15 y$ & $1314(21.2 \%)$ & $182(13.9 \%)$ & $98(7.5 \%)$ \\
\hline $16-25 \mathrm{y}$ & $1336(21.5 \%)$ & $166(19.0 \%)$ & $93(7.0 \%)$ \\
\hline$\geq 26 \mathrm{y}$ & $535(8.6 \%)$ & $69(7.8 \%)$ & $53(11.9 \%)$ \\
\hline \multicolumn{4}{|l|}{ Age when first acquired firearm } \\
\hline Never shot firearm & $3626(58.5 \%)$ & $523(14.4 \%)$ & $211(5.8 \%)$ \\
\hline$\leq 11 \mathrm{y}$ & $172(2.8 \%)$ & $28(16.3 \%)$ & $33(19.2 \%)$ \\
\hline $11-15 y$ & $456(7.4 \%)$ & $70(15.4 \%)$ & $45(9.9 \%)$ \\
\hline $16-25 y$ & $1111(17.9 \%)$ & $147(13.2 \%)$ & $90(8.1 \%)$ \\
\hline$\geq 26 \mathrm{y}$ & $835(13.5 \%)$ & $106(12.7 \%)$ & $65(7.8 \%)$ \\
\hline
\end{tabular}

a No participants selected this response option. 
Table 3.

Intercorrelations among categorical firearm exposure variables, computed as Cramer's V Age when first acquired firearm

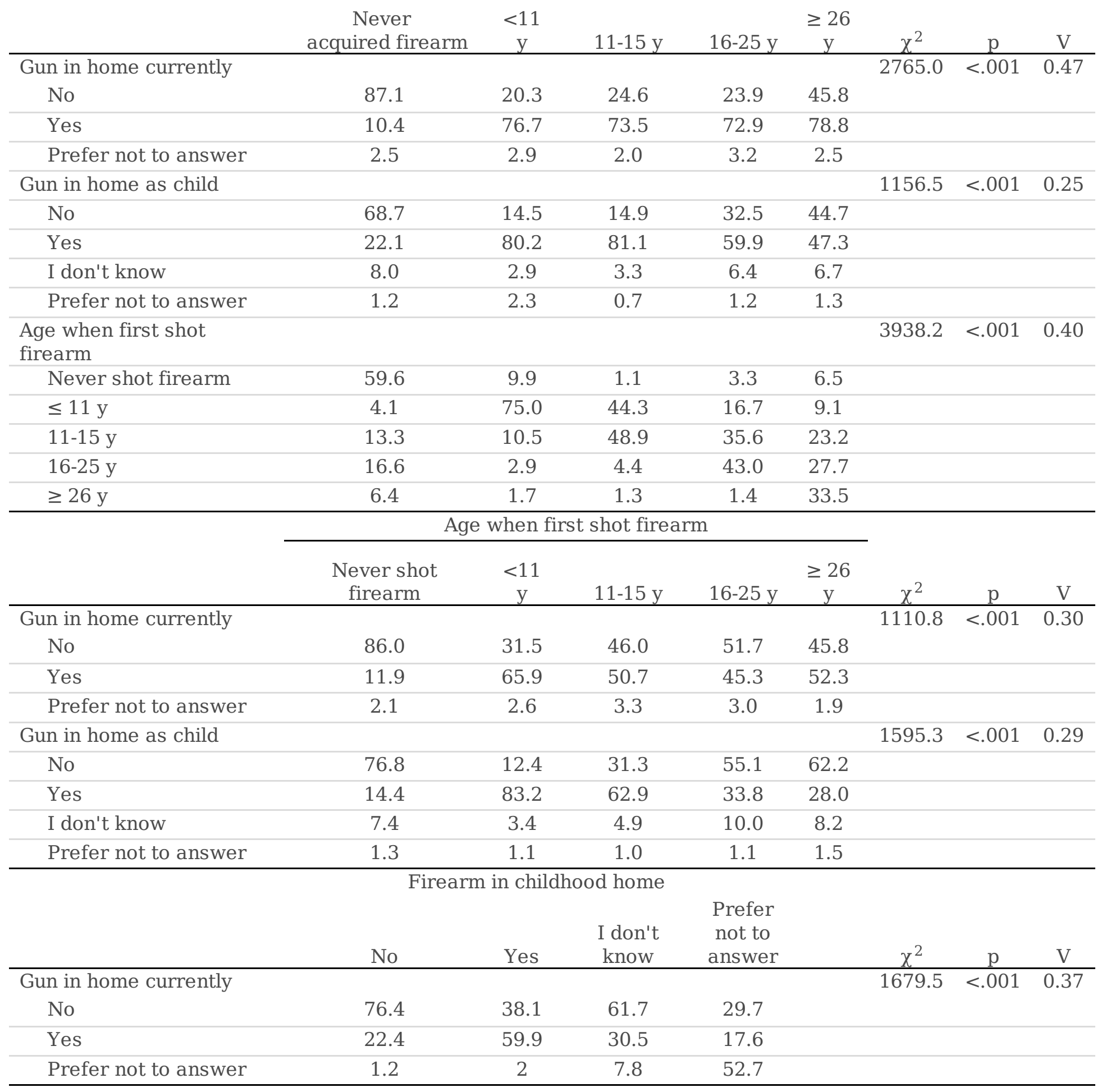


Table 4.

Results of unadjusted and adjusted logistic regression analyses 


\begin{tabular}{|c|c|c|c|}
\hline & OR $(95 \% \text { CI })^{\mathrm{a}}$ & $\mathrm{aOR}(95 \% \mathrm{CI})^{\mathrm{b}}$ & $\mathrm{aOR}(95 \% \mathrm{CI})^{\mathrm{C}}$ \\
\hline & \multicolumn{3}{|c|}{ Suicide Ideation } \\
\hline \multicolumn{4}{|l|}{ Firearm in current home } \\
\hline Prefer not to answer & $0.93(0.58-1.48)$ & $0.90(0.54-1.48)$ & $0.88(0.51-1.50)$ \\
\hline Yes & $1.03(0.89-1.19)$ & $1.08(0.88-1.32)$ & $0.96(0.77-1.19)$ \\
\hline No & 1.00 & 1.00 & 1.00 \\
\hline \multicolumn{4}{|l|}{ Firearm in childhood home } \\
\hline Prefer not to answer & $1.08(0.55-2.12)$ & $1.19(0.58-2.44)$ & $1.05(0.48-2.25)$ \\
\hline I don't know & $1.46(1.12-1.91)$ & $1.53(1.17-2.01)$ & $1.25(0.93-1.68)$ \\
\hline Yes & $1.28(1.10-1.48)$ & $1.42(1.18-1.70)$ & $1.35(1.11-1.65)$ \\
\hline No & 1.00 & 1.00 & 1.00 \\
\hline \multicolumn{4}{|l|}{ Age when shot first firearm } \\
\hline $26+$ yrs & $0.87(0.66-1.14)$ & $0.87(0.65-1.18)$ & $1.05(0.75-1.46)$ \\
\hline $16-25$ yrs & $0.79(0.65-0.97)$ & $0.76(0.61-0.95)$ & $0.94(0.73-1.20)$ \\
\hline $11-15$ yrs & $0.90(0.74-1.09)$ & $0.79(0.62-0.996)$ & $1.17(0.91-1.52)$ \\
\hline$<11$ yrs & $0.96(0.76-1.22)$ & $0.77(0.57-1.04)$ & $1.23(0.89-1.69)$ \\
\hline Never shot firearm & 1.00 & 1.00 & 1.00 \\
\hline \multicolumn{4}{|c|}{ Age when acquired first firearm } \\
\hline $26+$ yrs & $0.86(0.69-1.08)$ & $0.84(0.63-1.11)$ & $0.92(0.68-1.25)$ \\
\hline $16-25$ yrs & $0.91(0.74-1.10)$ & $0.89(0.69-1.15)$ & $0.76(0.57-0.995)$ \\
\hline $11-15$ yrs & $1.08(0.82-1.41)$ & $1.00(0.71-1.40)$ & $0.78(0.54-1.12)$ \\
\hline$<11$ yrs & $1.15(0.76-1.75)$ & $1.06(0.66-1.70)$ & $0.56(0.34-0.94)$ \\
\hline \multirow[t]{2}{*}{ Never acquired firearm } & 1.00 & 1.00 & 1.00 \\
\hline & \multicolumn{3}{|c|}{ Suicide Attempts } \\
\hline \multicolumn{4}{|l|}{ Firearm in current home } \\
\hline Prefer not to answer & $0.91(0.46-1.81)$ & $0.99(0.4802 .01)$ & $1.10(0.53-2.29)$ \\
\hline Yes & $1.50(1.23-1.82)$ & $1.04(0.80-1.36)$ & $0.94(0.71-1.25)$ \\
\hline No & 1.00 & 1.00 & 1.00 \\
\hline \multicolumn{4}{|l|}{ Firearm in childhood home } \\
\hline Prefer not to answer & $0.23(0.03-1.68)$ & $0.21(0.03-1.61)$ & $0.16(0.02-1.26)$ \\
\hline I don't know & $1.16(0.77-1.75)$ & $1.14(0.75-1.73)$ & $0.95(0.62-1.47)$ \\
\hline Yes & $1.82(1.49-2.22)$ & $1.65(1.31-2.12)$ & $1.57(1.22-2.03)$ \\
\hline No & 1.00 & 1.00 & 1.00 \\
\hline \multicolumn{4}{|l|}{ Age when shot first firearm } \\
\hline $26+$ yrs & $1.84(1.32-2.57)$ & $1.67(1.14-2.43)$ & $1.89(1.25-2.85)$ \\
\hline $16-25$ yrs & $1.25(0.95-1.65)$ & $1.02(0.75-1.39)$ & $1.24(0.90-1.73)$ \\
\hline $11-15$ yrs & $1.35(1.03-1.77)$ & $0.88(0.63-1.22)$ & $1.34(0.95-1.90)$ \\
\hline$<11$ yrs & $1.80(1.33-2.43)$ & $0.80(0.54-1.20)$ & $1.33(0.88-2.01)$ \\
\hline Never shot firearm & 1.00 & 1.00 & 1.00 \\
\hline \multicolumn{4}{|c|}{ Age when acquired first firearm } \\
\hline $26+$ yrs & $1.37(1.02-1.82)$ & $1.02(0.70-1.48)$ & $1.03(0.70-1.53)$ \\
\hline $16-25$ yrs & $1.43(1.10-1.84)$ & $1.25(0.89-1.76)$ & $1.09(0.77-1.55)$ \\
\hline $11-15$ yrs & $1.77(1.26-2.48)$ & $1.53(0.998-2.34)$ & $1.17(0.75-1.83)$ \\
\hline$<11$ yrs & $3.84(2.57-5.76)$ & $3.43(2.08-5.67)$ & $2.09(1.23-3.56)$ \\
\hline Never acquired firearm & 1.00 & 1.00 & 1.00 \\
\hline
\end{tabular}




\begin{tabular}{|c|c|c|c|}
\hline \multicolumn{4}{|l|}{ Firearm in current home } \\
\hline Prefer not to answer & $0.39(0.11-1.33)$ & $0.46(0.12-1.69)$ & $0.46(0.12-1.74)$ \\
\hline Yes & $1.39(1.04-1.86)$ & $0.89(0.60-1.32)$ & $0.89(0.59-1.34)$ \\
\hline No & 1.00 & 1.00 & 1.00 \\
\hline \multicolumn{4}{|l|}{ Firearm in childhood home } \\
\hline Prefer not to answer & $0.28(0.04-2.21)$ & $0.38(0.04-3.38)$ & $0.32(0.03-2.90)$ \\
\hline I don't know & $1.02(0.59-1.74)$ & $1.06(0.61-1.84)$ & $1.03(0.59-1.82)$ \\
\hline Yes & $1.54(1.14-2.08)$ & $1.43(1.001-2.04)$ & $1.40(0.97-2.01)$ \\
\hline No & 1.00 & 1.00 & 1.00 \\
\hline \multicolumn{4}{|l|}{ Age when shot first firearm } \\
\hline $26+$ yrs & $2.11(1.25-3.57)$ & $1.74(0.97-3.11)$ & $1.59(0.87-2.92)$ \\
\hline $16-25$ yrs & $1.66(1.12-2.47)$ & $1.41(0.91-2.19)$ & $1.43(0.91-2.25)$ \\
\hline $11-15$ yrs & $1.24(0.84-1.84)$ & $0.92(0.58-1.45)$ & $1.01(0.62-1.62)$ \\
\hline$<11$ yrs & $1.89(1.20-2.97)$ & $1.16(0.66-2.02)$ & $1.27(0.71-2.26)$ \\
\hline Never shot firearm & 1.00 & 1.00 & 1.00 \\
\hline \multicolumn{4}{|c|}{ Age when acquired first firearm } \\
\hline $26+$ yrs & $1.70(1.10-2.61)$ & $1.35(0.78-2.33)$ & $1.31(0.75-2.30)$ \\
\hline $16-25$ yrs & $1.54(1.05-2.27)$ & $1.34(0.83-2.19)$ & $1.38(0.84-2.29)$ \\
\hline $11-15$ yrs & $1.53(0.91-2.57)$ & $1.34(0.72-2.51)$ & $1.32(0.69-2.53))$ \\
\hline$<11$ yrs & $2.98(1.38-6.42)$ & $2.62(1.08-6.35)$ & $2.40(0.96-5.96)$ \\
\hline Never acquired firearm & 1.00 & 1.00 & 1.00 \\
\hline
\end{tabular}

Note: Values in bold are statistically significant at $\mathrm{p}<.05$.

a Univariate analysis

b Multivariate analysis adjusting for all firearm exposure variables

${ }^{\mathrm{C}}$ Multivariate analysis adjusting for all firearm exposure variables, sex, age, race, and annual household income, and negative affectivity 